\title{
Erratum to: Growth response to climate and drought in Pinus nigra Arn. trees of different crown classes
}

Darío Martín-Benito - Paolo Cherubini •

Miren del Río $\cdot$ Isabel Cañellas

Published online: 10 November 2009

(C) Springer-Verlag 2009

Erratum to: Trees (2008) 22:363-373

DOI 10.1007/s00468-007-0191-6

Unfortunately, the Fig. 3 was published incompletely in the original article. The complete figure is produced in the following page.

The online version of the original article can be found under doi:10.1007/s00468-007-0191-6.

D. Martín-Benito $(\bowtie) \cdot$ M. del Río · I. Cañellas

Departamento Sistemas y Recursos Forestales, CIFOR-INIA,

Crta. La Coruña km 7.5, 28040 Madrid, Spain

e-mail: dmartin@inia.es

P. Cherubini

Swiss Federal Institute for Forest,

Snow and Landscape Research WSL,

8903 Birmensdorf, Switzerland 

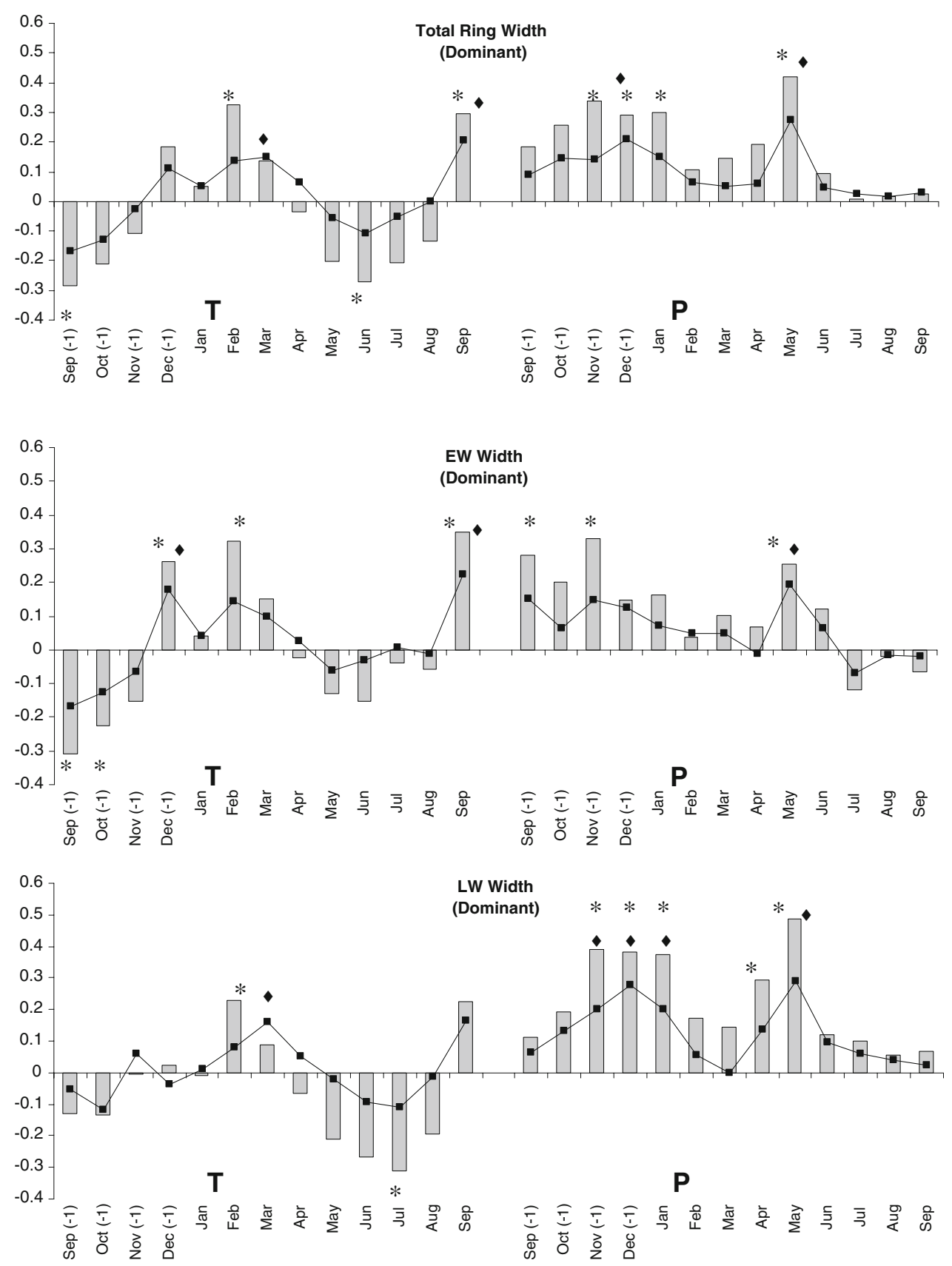

Fig. 3 Correlation (bars) and response (lines) functions for monthly temperatures $(T)$ and precipitations $(P)$ from previous September to September of the current year. Climate instrumental data and data for each ring compartment are from the period 1940 to 2005; total of 66 years. Asterisks and diamonds denote significance $(P<0.05)$ of correlation and response functions, respectively 


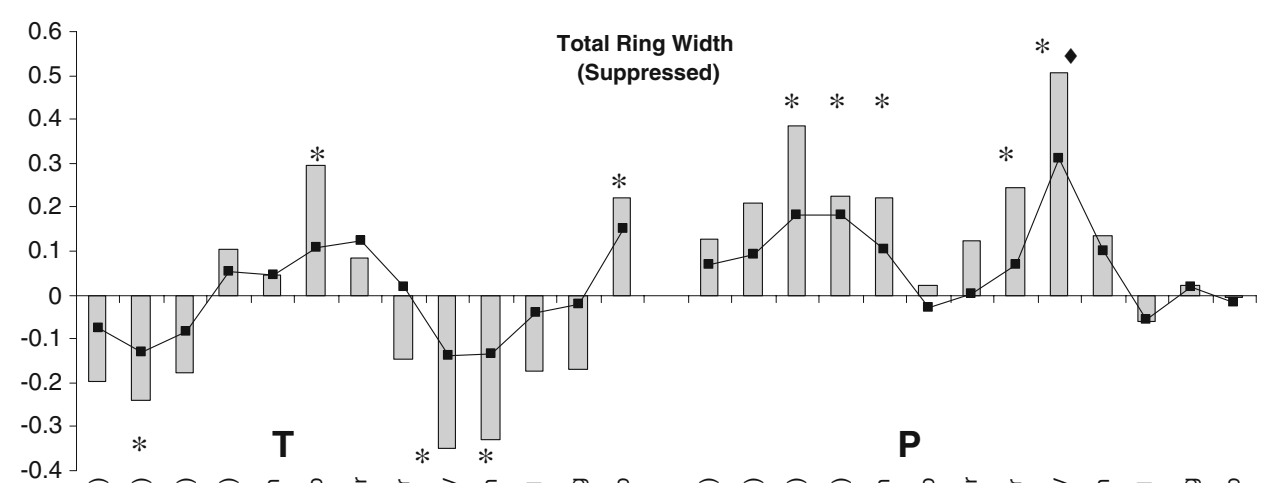

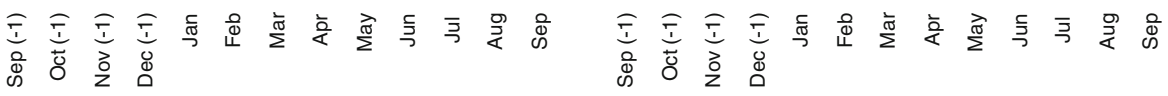
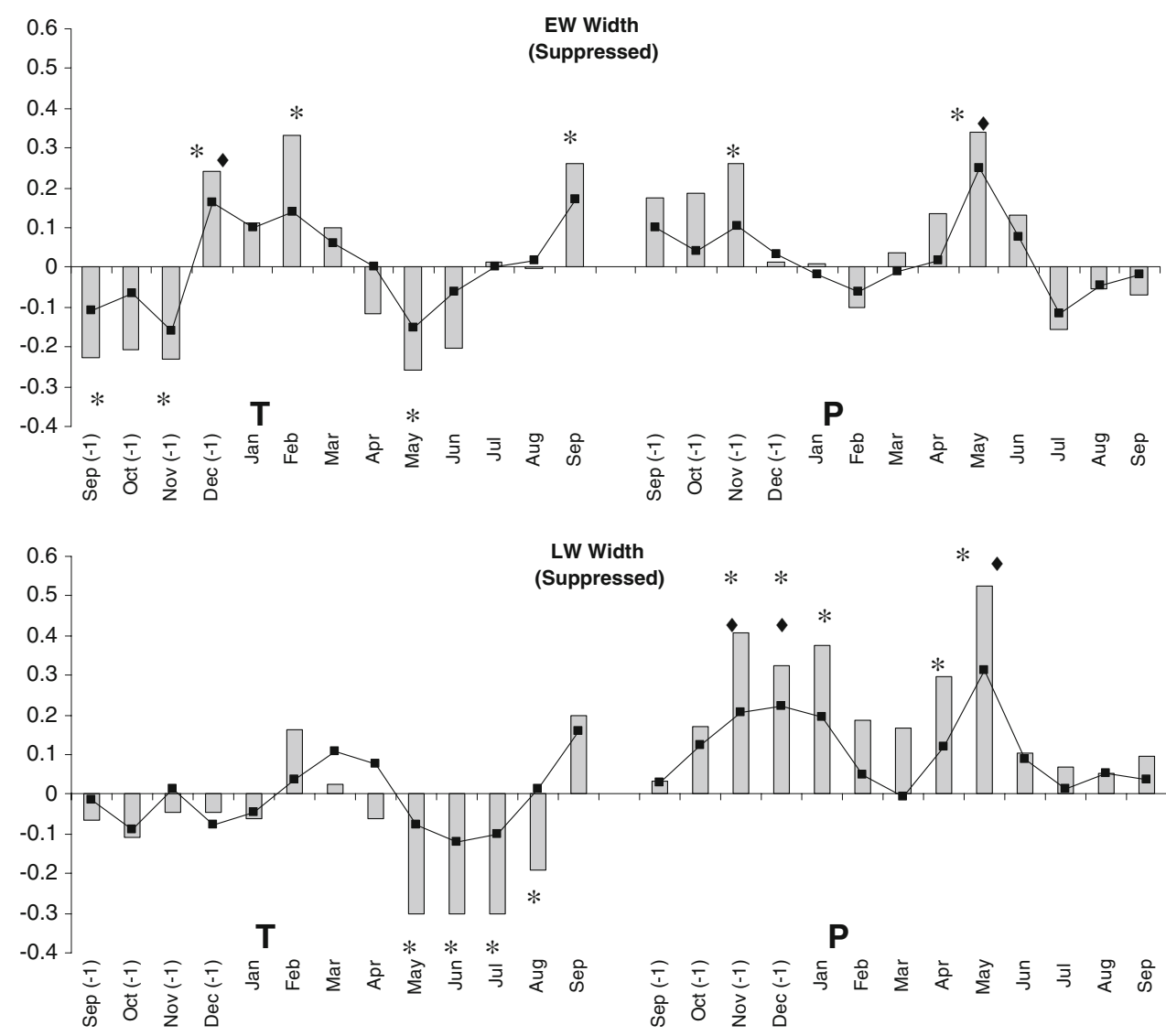

Fig. 3 continued 